\title{
Horizontes literarios en Chiapas: producción poética y narrativa de escritores jóvenes ${ }^{1}$
}

\author{
Literary horizons in Chiapas: poetic and narrative \\ production of young writers
}

\author{
Ana Alejandra Robles Ruiz \\ ORCID: 0000-0002-6040-5806 \\ Centro de Estudios Superiores de México y Centroamérica / \\ Universidad de Ciencias y Artes de Chiapas, México. \\ ale_robbles@hotmail.com
}

Resumen:

Como lo sugiere el título, el objetivo del presente artículo es exponer el panorama actual de la producción poética y narrativa de escritores jóvenes del estado de Chiapas. De entrada, se elabora una definición particular de juventud para situar de forma más precisa nuestro objeto de estudio. Posteriormente se reflexiona de manera general acerca del estado de la literatura joven en Chiapas. Finalmente se profundiza en una selección de obras poéticas y narrativas, escritas por jóvenes, que por su calidad, novedad y relevancia temática se distinguen de otras.

${ }^{1}$ En lo que respecta a la producción narrativa, cabe aclarar que en este artículo me limito al cuento y a la novela. Dejo de lado la crónica y el ensayo, no porque los considere textos menores, sino porque la brevedad del artículo me obliga a discriminar. Para tal discriminación me baso en que, partiendo de una revisión general, puedo percatarme de que la producción de cuento y novela de escritores jóvenes chiapanecos es más abundante que la de crónica y ensayo. 
Palabras clave:

literatura del siglo XXI, literatura contemporánea, universalidad, fragmentación, migración.

Abstract:

As the title suggests, the objective of this paper is to expose the current panorama of the poetic and narrative production of young writers in the state of Chiapas. First, a particular definition of youth is elaborated to more precisely locate our object of study. Secondly, the general state of young literature in Chiapas is ponded. Finally, the article delves into a selection of poetic and narrative works, written by young people, which by their quality, novelty and thematic relevance distinguishes them from others.

Keywords:

XXI Century Literature, Contemporary Literature, universality, fragmentation, migration.

DOI: https://doi.org/10.36798/critlit.vi21.310

Recibido: 02 de septiembre de 2019 Aceptado: 22 de mayo de 2020

\section{De atrás para adelante}

Ya mucho se ha hablado acerca de los grandes escritores chiapanecos como Jaime Sabines, de cuya poesía Aurora Ocampo dijo que estaba escrita no solo con el corazón sino con todas las entrañas y agregó, además, que Sabines convirtió en material poético todo aquello que conformaba su realidad cotidiana (49). De Rosario Castellanos, Enrique Krauze externó, a propósito de la medalla Rosario Castellanos que le entregó el Congreso del Estado de Chiapas en el año 2017, que sus libros sobre Chiapas son el rescate del dolor que infligen las identidades en nombre de las diferencias de etnia, clase, lengua, religión; y, además, que su prosa es objetiva y está 
nutrida de una mirada irónica muy fina. Respecto a Eraclio Zepeda y sus cuentos, Jorge Von Ziegler expresó que este, ante excesos vanguardistas, había vindicado la anécdota (5). También se ha dicho bastante de Óscar Oliva, Juan Bañuelos, Elva Macías, por mencionar a algunos de los más conocidos a nivel nacional e internacional; pero de los escritores chiapanecos más recientes y de sus obras se ha dicho poco.

Es difícil superar o estar a la par de autores tan notables como los que antes se refirieron, que han construido la identidad de la literatura chiapaneca, asumida tanto al interior como al exterior del estado. Sin embargo, la revisión de la producción literaria requiere ser una actividad constante, actualizada. Aplica en el caso de la literatura chiapaneca, como en la del resto del mundo. Los territorios van cambiando con el paso de los años, así como la gente que los habita y sus ideas, las instituciones que ahí se erigen, las costumbres, los modos de percibir lo inmediato. Esto se traduce en nuevos productos culturales, que poseen vasos comunicantes con la tradición, pero que al mismo tiempo construyen contenidos y formas originales desde el presente en el que se ubican.

Afirmo entonces: es necesario volcar nuestra mirada a la literatura joven. Es en ella donde nos será posible encontrar nuevas apreciaciones de la realidad, nuevas sensibilidades. Son los jóvenes quienes se arriesgan, quienes le apuestan a formatos distintos, quienes, con un background de lecturas nacionales e internacionales, canónicas y contemporáneas, están preparados para innovar. Claro está, en su mayoría, estos escritores se encuentran experimentando todavía, buscando un estilo propio, perfeccionando el oficio de la creación literaria. Están en la etapa inicial del proyecto, de ese proyecto que tiene como meta la trascendencia de su literatura. De provecho es entonces que vayamos examinando su evolución, preguntarnos a qué circunstancias, legados e intenciones responden las obras que están produciendo. Ahora bien, de entrada, es conveniente resolver una serie de interrogantes relacionadas con la delimitación del periodo que comprende la juventud, para posteriormente introducirnos de lleno en el tema que nos compete. 


\section{¿Escritores jóvenes?}

¿Qué es ser joven? Son muchos los estudios y las teorías que se han propuesto en los ámbitos de las ciencias sociales y humanísticas los que abordan esta cuestión y, a la fecha, no hay una definición científica unívoca, en dichos ámbitos, que proponga los criterios que acoten el concepto de juventud (Singly 2005). No obstante, considero que la apreciación de Pierre Bourdieu con respecto al tema es una de las más sugerentes y oportunas para la idea de juventud a la que nos apegamos en este trabajo. Bourdieu afirma que tanto juventud como vejez son posiciones sociales que están en producción y reproducción constante a partir de la pugna por la distribución de los poderes entre los sujetos que las ocupan. Así, la juventud requiere enmarcarse en un sistema de relaciones que defina en campos específicos los límites de edades. Es decir, la estimación de la juventud depende directamente de las leyes específicas de envejecimiento de cada campo (Bourdieu 2008). Pero, ¿qué ocurre en el caso de la literatura en México? ¿Hasta qué edad se sigue siendo un escritor joven?

Atendiendo a las particularidades de los campos de las que nos habla Bourdieu, lo más apropiado es que dirijamos nuestra mirada al mundo de la creación artística en el país, específicamente la creación literaria, para ubicar los rangos de edades de la juventud que en dicho mundo se han establecido. El FONCA, en su convocatoria de Jóvenes Creadores, considera jóvenes a individuos de hasta treintaicuatro años. La FLM disminuye la edad a treinta. Por su parte, el PEC$\mathrm{DA}$, en la categoría de Jóvenes Creadores, permite que participen en su convocatoria artistas de hasta treintaicuatro años. Por otro lado, el Sistema Nacional de Creadores de Arte (SNCA) del FONCA, que es un programa de estímulos y distinciones para artistas destacados, pide un mínimo de treintaicinco años para participar. En la esfera de los premios nacionales, en el Premio Nacional de Dramaturgia Joven Gerardo Mancebo del Castillo, aceptan textos de escritores de hasta veintinueve años de edad; en el Premio Nacional de Poesía Joven Elías Nandino, pueden participar escritores de hasta treinta años; mientras que en el Premio Binacional de Novela Joven Fron- 
tera de Palabras / Border Of Words y en los premios nacionales de Cuento Joven Comala, de Cuento Breve Julio Torri, de Novela Joven José Revueltas, de Crónica Joven Ricardo Garibay, de Ensayo Joven José Luis Martínez y de Novela Gráfica Joven la edad máxima para concursar es de treintaicuatro años.

Lo que puede deducirse de la información anterior es que, en el campo de las letras mexicanas, desde las instituciones que regulan y distribuyen tanto los incentivos económicos como el prestigio y los privilegios, se es joven máximo hasta los treintaicuatro años. A partir de los treintaicinco, los escritores tienen la posibilidad de acceder a otro nivel en la jerarquía del estatus artístico. Están, por así decirlo, preparados para situarse en una posición de madurez, no solo en lo referente a su trayectoria personal e íntima, sino a la de su producción literaria. Empero, la vida es un continuum, no se alcanza la madurez de un salto, como tampoco el perfeccionamiento del ejercicio literario de un día para otro. Por ello, ha existido una tendencia en el campo de la producción literaria y en el de sus estudios, al menos en México y en Latinoamérica, a conceder un margen de un par de años más a la categoría de escritores jóvenes. Para muestra, el libro Palabras Mayores. Nueva narrativa mexicana (2015), editado por Malpaso Ediciones S.L. y el Consejo Nacional para la Cultura y las Artes, con selección de Guadalupe Nettel, Juan Villoro y Cristina Rivera Garza, y prologado por esta última, el cual presenta veinte relatos de escritores mexicanos menores de cuarenta años cumplidos a la fecha de su publicación, ${ }^{2}$ que de alguna manera representan la literatura joven del país. ${ }^{3}$ Tomando en cuenta la

${ }^{2}$ Una de las narradoras seleccionadas es la chiapaneca Nadia Villafuerte, quien nació en el año de 1978. Algunas de sus publicaciones más sobresalientes son Barcos en Houston (Coneculta-Chiapas 2005), ¿Te gusta el látex, cielo? (Tierra Adentro 2008) y Por el lado salvaje (Ediciones B 2012).

${ }^{3}$ Otra muestra, igual de relevante, es Bogotá39, el evento colaborativo entre Hay Festival of Literature \& Arts, y Bogotá: UNESCO World Book Capital City, creado para identificar a los escritores de hasta treintainueve años más prometedores de Latinoamérica. La primera edición del evento se llevó a cabo en 2007, la segunda en 2017. Uno de los parámetros para el establecimiento de la 
información presentada, la literatura que se atiende en este artículo es la producida por escritores jóvenes, es decir, de hasta cuarenta años de edad, originarios de Chiapas. ${ }^{4}$

\section{Esta literatura}

Jesús Morales Bermúdez publicó en 1997 el libro titulado Aproximaciones a la poesía y a la narrativa de Chiapas. El objetivo de este libro, que se inserta en los campos de la investigación y la crítica literarias, es presentar, clasificar, valorar y reflexionar acerca de la producción poética y narrativa chiapaneca escrita en español, desde la época de la Colonia, hasta finales de los años noventa del siglo XX. Hago mención del libro de Jesús Morales Bermúdez, estudio significativo sobre las letras chiapanecas, porque para el desarrollo del presente artículo son fundamentales ciertas conclusiones a las que llega el autor, así como algunos anhelos que manifiesta en su texto y con los cuales inevitablemente dialogamos. Veintidós años después podemos discutir, cuestionar, reformular o afianzar las ideas de Morales desde la producción literaria actual de los escritores jóvenes del estado de Chiapas.

A partir de la revisión de varias antologías que reúnen la obra poética y narrativa de escritores jóvenes chiapanecos, ${ }^{5}$ así como del

edad de los laureados es el hecho de que el escritor Gabriel García Márquez terminó de escribir Cien años de soledad a sus treintainueve años.

${ }^{4}$ Para efectos de delimitación de la juventud, me circunscribo en este artículo a un rango etario. No obstante, la juventud es un fenómeno mucho más amplio y complejo, que más bien, considero, tiene que ver con una actitud ante la vida que se asume a partir de ciertas construcciones y autoconstrucciones.

${ }^{5}$ Aldana Sellschopp, Alejandro, compilador. La novela en Chiapas. Antología crítica. CONECULTA, 2018.

, compilador. El cuento en Chiapas (1913-2015). Antología crítica de Alejandro

Aldana Sellschopp. CONECULTA, 2017.

Carballo, Marco Aurelio, compilador. Cuentos del sur. CONECUlTA, 2012.

Gonzzalí Mayoral, Gustavo, compilador. Nueva literatura del Soconusco. Cuentos del taller coordinado por Marco Aurelio Carballo. CONECULTA, 2006. 
enfrentamiento que tuve con material literario de dichos jóvenes y de charlas con los protagonistas de la literatura que aquí se discute, es que me atrevo a hacer algunas aseveraciones. La primera es que la cantidad de escritores jóvenes en Chiapas es extensa. En los últimos años ocurrió una especie de Big Bang, desde la perspectiva de Fernando Trejo y Luis Daniel Pulido, que ha permitido el surgimiento y acrecentamiento del número de escritores, centros culturales y editoriales que hay en el estado, unos sobresalientes y otros improvisados (Pulido y Trejo 7-8). Este fenómeno no es exclusivo de Chiapas, es patente a nivel México y a nivel mundial y tiene que ver, de entrada, con la globalización (Zavala). Hay más escritores, independientemente de si son buenos o no, porque es un hecho que disponemos de un mayor número de herramientas de creación y de medios de difusión, relacionados con la adquisición y el dominio de las nuevas tecnologías que la globalización ha traído consigo. También es una realidad que el poder adquisitivo de dichas herramientas y la penetración a dichos medios es cada vez menos costoso y más práctico, además de que son los escritores quienes de forma individual se han dado a la tarea de fungir como editores y promotores de su propia obra, con el objetivo de darse a conocer y ganarse el respeto y el reconocimiento de los lectores. Este último punto nos lleva a la aseveración siguiente.

Los escritores chiapanecos jóvenes han rebasado las instituciones culturales. Son ellos quienes, sin recibir apoyo del Estado y sin adscribirse a un colectivo, han logrado publicar su obra (Trejo y

Morales, Claudia y Fernando Trejo, coordinadores. "Trece Narradores de Chiapas (1978-1994)", número especial de Punto de Partida. La revista de los estudiantes universitarios, editado por la Universidad Nacional Autónoma de México, no. 196, marzo-abril. 2016.

Pulido, Luis Daniel y Fernando Trejo, compiladores. Un manojo de lirios para el retorno. Poetas chiapanecos (1973-1990). CONECULTA, 2015.

Pulido, Luis Daniel y Fernando Trejo, compiladores. Antología arbitraria de poetas jóvenes de Chiapas. Ediciones y Sistemas Especiales, 2005.

Rivera, Fabián y Fernando Trejo, compiladores. Porque algún día faltarán cuentos... Antología (otra) del cuento joven en Chiapas. CONECULTA-Ediciones del animal, 2007. 
Pulido 8) —en su mayoría de forma independiente- y hacerle promoción con recursos propios. A raíz de esta situación actual, es que juzgo conveniente iniciar el diálogo con el texto de Morales Bermúdez al que ya antes se hizo alusión. Para 1997, según este autor, en el caso de México, incluido el estado de Chiapas, no hay por parte de los gobiernos un favorecimiento significativo y competente de proyectos encaminados al desarrollo de la cultura y el arte; mientras que sí existe un reconocimiento por parte del Estado de los aportes culturales hechos por los artistas ubicados en su territorio (Morales Bermúdez 16). Es decir, es el Estado quien presume de sus artistas, sobre todo de los que van cobrando popularidad y atención de la crítica a nivel nacional e internacional, pese a que no se ha comprometido de forma previa a destinarles protección, soporte y estímulos. En 1997 y en 2019, ${ }^{6}$ las circunstancias son similares. A los escritores chiapanecos jóvenes no les queda sino invertir dinero en sus propias creaciones o buscar mecenazgos, tocar las puertas tanto de editoriales de prestigio como de editoriales nuevas con la esperanza de que los consideren, participar en concursos literarios hasta resultar ganadores - por el dinero, sí, pero también por la promesa de publicación de su obra que se estipula como uno de los premios en las convocatorias de estos certámenes-, crear sus editoriales para autopublicarse y publicar a sus amigos, en fin. Aunque ideal sería que el Estado revalorara la magnitud de la contribución de los escritores a la cultura, para así actuar de forma solidaria con ellos, siempre habrá quienes, impulsados por un fuerte deseo y una necesidad de manifestarse artísticamente y compartirse con los otros mediante la palabra, seguirán haciéndose camino, pese a las dificultades, en el mundo de las letras chiapanecas. Con el ánimo de no caer en reduccionismos, aclaro que no estoy sosteniendo que el Estado no atienda, cuando menos parcialmente, a los escritores jóvenes chiapanecos que ambicionan ser publicados, pero sí manifiesto que aún queda mucho trabajo por hacer, hay una enorme deuda que requiere saldarse.

${ }^{6} 2019$ es el año en el que se redacta y envía el presente artículo a evaluación. 
Otra observación relevante que Morales hace en su libro es que, mientras la poesía en Chiapas es campo fecundo, la producción narrativa es menor, apenas, para 1997, comienza. Manifiesta, además, su anhelo de que se logre una narrativa tan bien escrita como la poesía (192). Con respecto a esta cuestión, puede decirse que el panorama no ha cambiado mucho. Chiapas sigue siendo un estado en donde la creación de orden narrativo es escasa (Mayorga en Rivera y Trejo 4). No se ha presentado un aumento significativo de escritores que opten por el formato de la narrativa. No obstante, en referencia al anhelo de Morales, tal vez sean los escritores jóvenes chiapanecos, y los que acaban de dejar de pertenecer a este grupo como Nadia Villafuerte, los que lo estén comenzando a efectuar; pues, como se expone en uno de los apartados posteriores, hay talento narrativo en el estado (Gonzzalí Mayoral 9). Muchas de las apuestas de dichos jóvenes poseen "una voz propia, nítida y potente ... [con la que se están encaminando a] prevalecer y transformar el entorno literario hispanoamericano" (Morales y Trejo 15). En cuanto a la poesía, continúan predominando las obras de este género entre los escritores jóvenes de Chiapas. El número de publicaciones individuales y antologías que se inscriben en este es alto en comparación con las que se presentan en narrativa.

Para dar muestra imprescindible y pertinente de qué es en sí lo que los escritores jóvenes del estado de Chiapas están haciendo en lo concerniente a poesía y narrativa, decidí hacer una selección de cuatro poetas y cuatro narradores, ${ }^{7}$ para hablar partiendo de un análisis hermenéutico y procurando situarme en el campo de la crítica literaria de alguna de sus obras. Consideré autores chiapanecos de hasta cuarenta años y que cuentan con publicaciones formales. Para

7 Me parece que es un número apropiado para tener un panorama de la literatura chiapaneca actual. El formato de artículo al que fue necesario que me sujetara me impide hacer una exposición más cuantiosa. No obstante, quiero puntualizar que la producción literaria joven en el estado no se limita a los autores y obras que elegí. Hay un abanico más amplio de opciones que sugiero a los interesados explorar y juzgar por sí mismos. 
la selección de autores y obras se tomó en cuenta calidad, novedad y relevancia temática. ${ }^{8}$

\section{Calidad, novedad y relevancia temática}

En lo concerniente a los criterios de selección de autores y obras, es preciso plantear la definición de cada uno de estos elementos. Primero, propongo que un texto literario posee calidad cuando cumple de forma exitosa con el total o la mayoría de las cualidades que sugiere Jonathan Culler como intrínsecas a la literatura: 1) la literatura trae a primer plano el lenguaje, esto quiere decir que la disposición lingüística pasa a primer término y como lectores ponemos atención especial en su estructuración; 2) integra el lenguaje, en otras palabras, hay en ella relaciones intencionales entre niveles lingüísticos, organización gramatical y estructura temática, lo que produce significaciones de diversos tipos; 3) es ficción, puesto que guarda una relación ficcional con el mundo; 4) es un objeto estético, en tanto que conduce al lector a considerar la interrelación de forma y contenido, a atender el efecto global de la obra, además de que produce deleite o goce; 4) es una construcción intertextual y autoreferencial, lo que significa que tiene conexión con otras obras y le es posible reflexionar sobre sí misma (Culler 40-48). Segundo, a partir de los supuestos de Ortega y Gasset (1964), como novedad entiendo no necesariamente lo dicho por vez primera, sino lo que se dice en un sentido nuevo o vigoroso, lo que rompe las estructuras reales e interpreta de forma peculiar. En otras palabras, la novedad es el estilo del artista y el estilo es lo que procede de la individualidad del yo, pero que se verifica en las cosas: "Los esti-

${ }^{8}$ Quiero agregar que la mayoría de los escritores que seleccioné coinciden en haber tomado cursos con escritores más longevos como Alejandro Aldana Sellschopp, Marco Aurelio Carballo, entre otros. También, casi en su totalidad, estos jóvenes han obtenido becas de creación, como por ejemplo la de Jóvenes Creadores del FONCA, así como premios estatales y nacionales de poesía y narrativa. 
los son vórtices dinámicos que ponen novedad en el mundo, que aumentan idealmente el universo" (Ortega y Gasset 247). Tercero, considero que una obra tiene relevancia temática cuando el centro de su reflexión es el ser humano en su vertiente individual, social o cultural, y por lo mismo desarrolla cuestiones como realidades, complejidades y visiones de mundo.

\section{Selección poética}

Fernando Trejo nació en Tuxtla Gutiérrez, Chiapas, en 1985. Tiene una amplia producción poética. En el caso de este artículo, resolví profundizar acerca de uno de sus poemarios temáticamente más sugerentes: Ciervos (2015). Este sobresale de otros porque el autor decidió escribir los poemas ${ }^{9}$ que lo conforman a partir de tres famosos asesinos que toda su vida o en algún lapso de esta se dedicaron al arte: Richard Dadd, Johann "Jack" Unterweger y José Luis Calva Zepeda. Ingeniosamente, Trejo utiliza la primera persona del singular en casi todos los poemas de las tres partes en las que está estructurado Ciervos, para darle voz a Dadd, Unterweger y Calva, respectivamente. Cito a Unterweger, el yo poético:

No conocí a mi padre. Dicen que eyaculó en mamá una tarde de noviembre de 1949. Le dejó desde entonces la sonrisa chueca y los ojos partidos como una botella de cristal. Nací el 16 de agosto de 1950 sobre charcos de alcohol barato y un abuelo que sostenía conversaciones más allá de las tumbas. En Austria la prostitución es legal. Madre era una puta legal. Yo soy un bastardo legal. Mi padre era un soldado norteamericano que atravesó con su rifle los cordones del infierno. Legal. (Trejo 23)

De esta manera, un poco tejiendo la información resultante de

\footnotetext{
${ }^{9}$ Prosa poética, en el sentido estricto de las palabras.
} 
una evidente escrupulosa investigación bibliográfica con el artificio del poeta, el autor logra como resultado un poemario que despierta el interés del lector, gracias a que nos presenta una propuesta de cómo funciona la mente criminal y enferma. A la vez, sugiere que hay una relación entre esta mente enferma y la vena artística del ser humano, demostrando que la llamada faceta oscura del hombre coexiste con su bondad y, que pese a ser tan compleja y misteriosa, seguiremos intentando explicárnosla desde la religión, la ciencia o el arte. Aunque la extravagancia sobre la que Trejo construye Ciervos tiene un gran impacto y merece mayor atención, no quiero pasar por alto otras cualidades que convierten al poemario en una obra bien lograda, como lo son los diferentes recursos retóricos y poéticos que es posible identificar en ella; por ejemplo, el buen empleo de la écfrasis, en este caso, en su acepción de representación visual de una obra plástica:

Voy a pintar un cuadro donde un hombre soporte un hacha. El hombre será un leñador que soporte un hacha. Gnomos y hadas en el submundo del leñador que soporta el hacha lo observarán. Sombrío. Lianas y arbustos. La música abierta. Flores muertas de tan blancas. Naceré ahí, en el golpe. Un hombre observará, dos hombres observarán. La mirada es una línea que sostiene mis hadas. El duende tiene miedo de mí. Sus ojos me ven tanto al oído que lo escucho. El leñador está a punto de quebrar el aire nueve años después. Fin. Cae el hacha sobre Robert Dadd. Parto en dos su cráneo. El lienzo tiene mi firma. (Trejo 15)

El poema "El leñador sostiene un hacha", que citamos en su totalidad, claramente está haciendo una representación del cuadro El golpe maestro del leñador duende (1855-1864), del pintor Richard Dadd, de forma ecfrástica, pero además está sugiriendo la relación entre este y el parricidio ejecutado en 1844 por el artista, precisamente con un hacha, una navaja y un cuchillo. Lo anterior hace también que la écfrasis no se limite a la representación pura o sencilla, sino que funcione, en palabras de Valvidia, como traducción pictórica o 
visual. Es decir, a través de la écfrasis, el poeta reinterpreta la obra plástica y revela un significado profundo, que va más allá de lo aparente tratado por el artista plástico (Valvidia cit. en Agudelo 82-83). En este sentido, podemos hablar de que Trejo reinterpreta, en "El leñador sostiene un hacha", el cuadro de Dadd como la recreación simbólica del crimen que este cometió. En esto consiste la traducción pictórica y el sentido de la écfrasis.

César Trujillo nació en Yajalón en $1979 .{ }^{10}$ De su obra he elegido el poemario Evocación de la infancia (2018) para ahondar en él. Su valor radica en la intimidad de los poemas que lo conforman, en la sencillez y peso significativo de sus metáforas, así como en la diversificación de voces y formatos presentes en ellos. Evocación de la infancia dialoga con una de las obras más emblemáticas de otro poeta chiapaneco, Algo sobre la muerte del mayor Sabines (1973), de Jaime Sabines, en el sentido de que, al igual que este último, el poemario de Trujillo aborda el tema de la muerte de seres queridos (abuela, hermano, abuelo, padre), y lo hace también como Sabines, con las entrañas: "Tu rostro se ha borrado de la fotografía familiar./ Es el destino de todos los que abi aparecen, asegura mi padre./Abuela,/¿por qué moriste/sin decirnos la forma/en que se conserva la memoria?" (Trujillo 31). No obstante, César Trujillo le imprime su propio estilo a Evocación de la infancia, lo que lo distancia de caer en la cómoda imitación de obras aplaudidas por la crítica, para, en vez de eso, exponer una propuesta singular que, de manera astuta, simple y sencillamente conversa con otras obras que se insertan en la tradición como la de Sabines.

En relación con la sencillez y peso significativo de las metáforas que emplea Trujillo, conviene citar el siguiente ejemplo:

Para llegar al río había que pasar los alambrados, evitar tropezar con el zacate estrella; caminar por la vereda que subía o bajaba,

${ }^{10}$ Para el 2019, año de redacción y envío del presente artículo, Trujillo cuenta con 40 años, por lo que entra en la clasificación de escritores jóvenes. 
según la dirección del caminante.

En ese tiempo

: el torrente era una nauyaca

con árboles

danzando dentro de su vientre. (Trujillo 74; énfasis mío)

Los últimos tres versos tienen una construcción sencilla, pero son significativos porque la elección de las palabras es cuidadosa. El yo poético nos convida a hacernos una imagen mental de un paisaje específico, el campo y el río. Él percibe este último como una serpiente larga, dinámica, fuerte, peligrosa. Sin embargo, no es cualquier serpiente, sino la nauyaca, característica del sur de México, América Central y el norte de Sudamérica; lo que enfatiza que el espacio pensado se ubica en el estado de Chiapas. A su vez, continúa la descripción del río utilizando la metáfora de la nauyaca y nos invita a pensar esta con árboles que bailan en su interior, tal y como aparentan hacerlo los árboles dentro del agua del río debido al movimiento de la corriente.

Acerca de la diversificación de voces y formatos, César Trujillo no se limita al verso, sino que experimenta también con la prosa poética:

Cargo la rabia bajo las uñas. La escondí para que no lastimara la ausencia de papá, para que nadie pudiera hacerse daño, para que nadie supiera que me dueles como el hachazo desgajando algunas ramas. Está mejor ahí: sepultada para que no revele más verdades. (54)

El poeta recurre a este formato movido por una necesidad de expresión más fluida y que refleje esa cualidad que en ocasiones tiene la angustia de manifestarse involuntariamente y sin pausas. Con respecto a las voces, el yo poético es casi siempre el mismo: ese que perdió a sus seres amados. Empero, el yo poético se toma la libertad, a veces, de citar a otros, y el autor, como ocurre en el primer apartado, de ceder la voz a los muertos y sugerir que incluso en 
el más allá siguen queriendo, pensando, sufriendo. Esto, sin duda, vuelve la obra heterogénea y más interesante: "Quise decirles que se fueran a casa, que el frío de los muertos se mete entre los huesos. Pero me dejaron con la lengua cocida entre los labios, los ojos atiborrados de pintura, ensartada en un vestido que nunca me gustó. Quise decirles, lo juro, pero la tierra devoró mi voz"' (Trujillo 18).

René Morales Hernández nació en Ocozocoautla de Espinoza, Chiapas, en el año de 1981. Su libro titulado Texas I Love You, publicado en 2018, sin duda ha logrado captar la atención de colegas, críticos y lectores en general. ${ }^{11}$ Lo que más sobresale y causa impresión de este poemario es su naturaleza híbrida. Stephen Kock acuña el término de texto híbrido para hablar de una nueva forma de escritura surgida en los primeros años del siglo XX (en Noguerol 239) y que continúa hasta nuestros días. Esta nueva forma de escritura evidencia el rechazo a la literatura canónica, así como una afinidad con el pensamiento posmoderno. Se caracteriza por la variedad, la fragmentación y la flexibilidad en su construcción poética o narrativa (en Noguerol 239). En el caso de la obra de Morales, la hibridez se reconoce precisamente en la construcción total del poemario, así como en la disposición de los poemas y otra información presente. Texas I Love You inicia con la siguiente nota del autor:

... este libro está basado en las historias de personas de origen latinoamericano que recibieron la inyección letal en Texas. Toda la información fue obtenida de expedientes del Departamento de Justicia Criminal del estado sureño. Utilicé los nombres como aparecen en los archivos oficiales, así como sus últimas declaraciones. Sin embargo, para ciertos efectos literarios, me tomé algunas libertades creativas cuya responsabilidad recae sobre mi persona. (Morales Hernández 17)

Desde que el lector se enfrenta con esta nota, adivina que lo que

${ }^{11}$ Ciertos poemas de Texas I Love You requieren más fineza, sin embargo, en su mayoría presentan precisión y cuidado. 
leerá a continuación es un poemario experimental, que está fuera de los parámetros de la convención y que, al mismo tiempo, se cuestiona acerca del binario ficción/realidad. El autor se encarga también de incluir citas de políticos estadounidenses a modo de epígrafes, que incitan a la reflexión acerca de aspectos como los derechos humanos, la justicia, el bien, el mal, entre otros; por ejemplo: "Si usted no apoya la pena de muerte o el hecho de que los ciudadanos no puedan llevar una pistola en su bolsillo, no venga a Texas" (Morales Hernández 31), afirmación hecha por el gobernador Bill Clements. Es decir, hay una evidente intención por parte de René Morales de usar datos precisos y reales como herramientas para construir un poemario que nos obliga a que lo leamos de forma distinta a la acostumbrada.

Texas I Love You se divide en cinco capítulos. Cada uno de los poemas que los conforman se estructuran de la misma manera. El título es siempre el nombre de alguno de los sujetos masculinos inmigrantes latinoamericanos que recibieron la inyección letal en Texas. Del lado derecho de la página y en cursivas, hay una ficha que proporciona información en relación con los delitos que estos cometieron. En el lado izquierdo se aprecia un poema escrito en verso. En este a veces asoma entre líneas un vínculo con las historias reales de los condenados, otras veces es solo una propuesta o interpretación del poeta. Por último, en una nota al pie conocemos las fechas en las que murieron los inmigrantes, así como sus últimas declaraciones. Esta compleja estructura, exige pues, que se considere cada uno de sus elementos, sin importar si provienen de documentos legales o de la imaginación del poeta, pues es solo en su conjunto que cobran sentido como un todo, híbrido, sí, pero a fin de cuentas redondo y estéticamente propositivo. Así, René Morales Hernández participa del tema de la inmigración, al mismo tiempo que de los temas de la criminalidad, los vicios y las pasiones humanas, pero no lo hace como cualquiera, les imprime un toque único, original, que mucho tiene que ver con una postura ante la insuficiencia de las demarcaciones discursivas y genéricas en la literatura para expresar los acontecimientos y sentires actuales, a la vez que con la incapacidad del discurso oficial de responder a 
nuestras dudas y cuestionamientos acerca del presente que nos está tocando vivir.

Por último, hago mención de Y sabrás un día (Tumjama maka mujsi), poemario escrito en zoque y español por Mikeas Sánchez, nacida en Chapultenango en 1980. La obra de Sánchez, desde el primero a la primera mitad del tercer apartado es de corte conceptual-místico-filosófico, explora la existencia y el funcionamiento del alma: "He aquí el alma/ código paterno de la herencia/ círculo polar dividiendo mi boca/emoliendo fragmentos de dolor" (Sánchez 39); así como también la idea de dios: "Él mira por encima del oasis/ por encima del verde/ sus espejos ven oscuridades/ [del cuarzo humano/ Por eso digo/ que la noche comienza/ cuando cierras los ojos" (Sánchez 31). En este sentido, Y sabrás un día (Tumjama maka mujsi'), es un poemario poco experimental, apegado a la tradición, pues si hacemos un recuento de la literatura universal, las temáticas de lo divino y el alma han estado presentes desde los poetas clásicos hasta la escritura contemporánea. Son cuestiones que no dejan de interesar al ser humano y para las cuales no hay consenso o explicaciones definitivas. No obstante, el hecho de que los poemas de Sánchez retomen tópicos como los ya mencionados, no demerita su trabajo, simplemente nos lleva a situar a la autora en un punto más cercano o en diálogo con la tradición literaria. Además, Mikeas Sánchez tiene oficio poético, construye sus poemas con suma meticulosidad, lo que da como resultado un poemario de evidente calidad estética.

En la segunda mitad del tercer apartado de Y sabrás un día (Tumjama maka mujsi) la autora explora el ritual de la infancia y la vida presente del yo poético:

Duermo con el padre nuestro en los labios

y mi madre acomoda su altar

$$
\text { [de olvidos }
$$

Ella teje oraciones escarpadas

a cada movimiento del rosario

su mirada adquiere destellos solares

como si las bolitas de plata

entraran una a una en sus ojos. (Sánchez 79) 
Finalmente, el último apartado —el cuarto— versa sobre el recuerdo de alguien que se ha ido: "Escucho susurros de tu nombre/ [en antros y griseslunas/ Y la música despedaza nudos de garganta/ se sumerge en los instintos" (Sánchez 109). Estas vertientes del ritual y del ser que se fue, consolidan la lectura de la obra de Mikeas Sánchez como una obra poética con apego a la tradición.

Párrafos atrás se sugirió $Y$ sabrás un día (Tumjama maka mujsi) como un poemario con calidad estética. Para centrarnos en uno de los elementos que le otorgan dicha cualidad a la obra mencionada, hablaremos de la musicalidad presente en ella. Con respecto a la métrica, es variada, no es la intención de Sánchez ceñirse a un número de sílabas determinado. En cuanto a la rima, a veces se presenta en uno u otro poema, pero tampoco se sigue un patrón fijo. Ahora bien, en lo que respecta al ritmo, este cobra relieve en casi todos los poemas, lo que causa un efecto sonoro distinguido al momento de leerlos. Agrego que, a partir de mi lectura, identifico que son los recursos poéticos de la repetición y la aliteración, los más recurrentes y gracias a los cuales es posible esta musicalidad en los poemas de Mikeas Sánchez:

No me encuentro en arriate de locos no me encuentro en arriate de vivos soy errante desterrado del paraíso del infierno

vigía arrastrando rieles de muerte Busco ese último hito de melancolía Esa última soledad que me atorranta Y busco al cuáquero que dividió mi cráneo [en mil espejos. (Sánchez 89; énfasis mío)

En el poema citado, la repetición (marcada con cursivas) provoca un ritmo continuo y, al mismo tiempo, cumple con la función de dar solidez a lo que quiere expresarse, en este caso, la no pertenencia y la búsqueda. Mientras que la aliteración (marcada con negritas), específicamente del sonido fuerte de la " $r$ ", la percibimos 
como un ruido incómodo, que se vincula con ese rechazo y esa sensación de angustia que el yo poético está experimentando. De esta manera, a través de la repetición y la aliteración, Mikeas Sánchez logra imprimir musicalidad a sus poemas, lo que sin duda deleita nuestra percepción estética.

\section{Selección narrativa}

Alexis de Ganges, escritor san cristobalense nacido en 1980, publicó en 2009 el libro de cuentos titulado Solo las cenizas. Partiendo de una lectura comprometida, menciono que este libro sobresale por la universalidad de sus relatos, por el buen empleo de la ironía, por el humor que el autor imprime a las narraciones, por la sencillez con la que está escrito, por las intertextualidades que se presentan con recurrencia, entre otros aspectos. ${ }^{12}$ Sin embargo, estimo significativo detenernos aquí en el buen manejo que el autor hace de la ironía en sus textos. La ironía ocurre en el contraste entre aquello que se hace o dice y el mensaje que verdaderamente se quiere transmitir (Muecke cit. en Barreras Gómez 245). Atenderemos específicamente uno de los cuentos de Solo las cenizas para ubicar esta ironía. En "El eco de los huesos", cuento que narra la historia del adulterio del juez Ricardo Pérez, así como la de su asesinato y el impacto que este tuvo en sus hijos, la ironía se presenta precisamente en el contraste entre la falta que comete a su matrimonio y su profesión, así como entre esta y la causa de su muerte. El primer contraste adquiere sentido irónico cuando el narrador menciona: “¿Él, que siendo juez no podía permitirse un desvío de la línea recta, sería capaz de algo semejante?” (32). Ganges otorga deliberadamente la profesión de juez a su personaje con el objetivo de destacar el adulterio en el relato, para que como lectores reparemos en este y, ya sea que seamos más duros al juzgar el adulterio por haber sido cometido por alguien

${ }^{12}$ Considero que particularmente el cuento "Baco o el triunfo de los borrachos" pudo trabajarse más, pero el resto de los textos me parecen logrados. 
de quien se espera un ejemplo intachable de vida, o que aceptemos que nuestra complejidad humana puede llevarnos en múltiples ocasiones a tomar decisiones paradójicas, porque como dice Comte-Sponville el yo "es múltiple, cambiante, inasible . .." (163). El segundo contraste adquiere sentido irónico cuando leemos el epitafio de Ricardo: "Aquí yace un hombre que buscó la justicia y murió por ella" (33) y tomamos en cuenta las implicaturas presentes en el cuento. Sepamos que "El proceso de la comprensión de la ironía tiene que ver con el descubrimiento de la/s implicatura/s que aparece/n en el texto" (Barreras Gómez 247). La primera implicatura es que Socorro, la mujer de Ricardo, se enfureció tanto al enterarse de que se casó con un hombre que le fue infiel, que hizo que lo transfirieran del trabajo a Ciudad Carranza, en donde le dieron muerte, por venganza y para que el pueblo no se enterara de lo que había hecho. La segunda implicatura es que Ricardo, en su calidad de juez en Ciudad Carranza, se percató de que el abogado Martínez había cometido una serie de irregularidades que le ocasionaron condenas injustas a tres hombres. Ricardo reportó a Martínez y este perdió su empleo. Posteriormente el hijo de Martínez asesinó a Ricardo. Considerando estas implicaturas, es factible interpretar que Ricardo murió, como dice su epitafio, por la justicia, primero, en el sentido de que de alguna manera hay un ajuste de cuentas por el daño que le hizo a su mujer; segundo, en el sentido de que por procurar resarcir la injusticia que se cometió contra los hombres de Ciudad Carranza, el hijo de Martínez se vengó dándole muerte.

Otro escritor a quien considero valioso incluir en el muestrario de narradores es a Mikel Ruiz. Él nació en Chicumtantic, Chamula, Chiapas, en el año de 1985. En 2014 sale su libro Los bijos errantes (Ch'ayemal nich'nabiletik), escrito en tsotsil y español. Este libro narra la historia de Ignacio Ts'unun, un indígena tsotsil que anhela ser mestizo y desprecia a los suyos y, a raíz de la violación que comete contra Elena, desata una serie de eventos desafortunados que llevan al lector a replantearse su condición humana. Considero que el libro es digno de reconocimiento gracias a distintos factores, dentro de los cuales me detengo en dos: el abordaje de la temática y los personajes indígenas, así como la estructura de la obra. Escritores 
jóvenes como Ruiz, quienes además pertenecen a pueblos originarios como el tsotsil, han hecho apuestas interesantes a la hora de trabajar con temáticas y personajes indígenas.

En Los hijos errantes (Ch'ayemal nich'nabiletik), Mikel Ruiz intenta, más que representar una realidad indígena particular o condenar Occidente, ${ }^{13}$ exponer el lado llamado oscuro de los seres humanos, que motivado por ciertas circunstancias emerge recordándonos que la naturaleza del hombre es compleja, como ocurre con el personaje de Ignacio Ts'unun, quien comete el delito de violación, y de Manuel Tsepente', quien es violento con su mujer e intenta asesinarla. Como acertadamente anota Alejandro Aldana Sellschopp: "El tejido narrativo [de la novela de Mikel Ruiz,] está más allá de la mal llamada literatura indígena ..." (en Ruiz 19). Para el autor, "la comunidad no es un pedazo de paraíso terrenal en el que todos viven en armonía, los observa y nos los presenta con sus contradicciones, dejando muy lejos la idealización del indígena ... En las narraciones de Mikel el indígena no es un santo, es un hombre" (Sellschopp en Ruiz 23-24). Ese es uno de sus grandes méritos.

El segundo factor que reconozco en el libro de Ruiz es en relación con su estructura. De manera singular, el libro de Mikel Ruiz tiene la virtud de la dualidad de género. Es un libro que puede leerse como una novela, pues las cinco partes que lo conforman se interrelacionan sumando información que aporta a una misma lectura. No obstante, debido a la autonomía de cada una de estas cinco partes, el libro también puede leerse como relatos perfectamente íntegros. Sin duda, esta dualidad merece elogiarse, sobre todo porque es evidente un trabajo serio, inteligente y bien planeado por parte del autor. No hay muchos escritores que se hayan arriesgado a jugar con este tipo de estructuras flexibles, o más bien, que hayan conseguido que su realización fuera exitosa. ${ }^{14}$

${ }^{13}$ Como ocurrió en el caso de la literatura indigenista.

${ }^{14}$ Dos escritores que al igual que Mikel Ruiz sin duda han tenido éxito en esta empresa son, por un lado, Max Aub con Juego de cartas (1964) y, por otro, Enrique Serna con Amores de segunda mano (1991). 
De las escritoras jóvenes chiapanecas, destaco a Claudia Morales, porque considero que su prosa es significativa. Ella nació en Cintalapa de Figueroa en 1988. En el año 2015 fue Premio Nacional de Novela Breve Rosario Castellanos por No habrá retorno, obra de la que precisamente se habla en las siguientes líneas. En el caso particular de esta novela, sobresale la excelente ejecución de la estructura fragmentada. Morales no solo ambicionó contarnos las historias de vida de la investigadora mexicana Claudia y de su abuela Elena, así como la de la estadounidense Dorrey, adoptada por los Marren, y la de otros personajes más, sino que entretejió finamente estos relatos atravesándolos por el tema de la migración. Pero, además, de forma intencional y con prolijidad, tomó la determinación de alejarse del modelo sencillo y tradicional de escritura y, en vez de eso, enmarcó dichas historias en una estructura fragmentada, obteniendo como resultado una novela singular y bien lograda.

Estructuralmente, podemos decir que no hay linealidad en $N o$ habrá retorno. La obra inicia con la entrevista que un interlocutor desconocido y sin marca le está haciendo a la anciana Dorrey acerca de su convivencia con la fotógrafa Marcey Jacobson. De pronto, en el siguiente apartado aparece el personaje de Claudia y el narrador nos cuenta acerca de su pasado familiar. Más adelante conocemos al salvadoreño Óliver y a Gavilán, el guatemalteco, quienes quieren cruzar a Estados Unidos en busca de una mejor oferta laboral. Luego vemos lo que parece ser un guion de telenovela y así sucesivamente. No se sigue tampoco un orden cronológico. La autora en los distintos apartados se mueve con flexibilidad del presente al pasado o al futuro, hay retrospección y prospección a la vez. Por último, importante es que Claudia Morales suprima hasta cierto momento los enlaces lógicos, lo que motiva de alguna manera al lector a intentar reconstruir la novela. Así, con este tipo de narraciones nos damos cuenta, como dijo Castellet, que es la hora del lector (cit. en Veres 115). Pero lo que causa aun mayor asombro y admiración de la novela de Claudia Morales es que al final la autora libera las últimas pistas que estuvo cuidando con celo, que nos hacen reconocer en esta especie de collage narrativo también una estructura unitaria y cerrada, una historia perfectamente redonda, lo que nos da la sensa- 
ción de estar ante un producto acabado. Harold Bloom pronosticó en 2002 que la literatura del futuro estaría formada por productos breves, elípticos y fragmentarios, tal y como se vinieron mostrando la televisión y los formatos periodísticos las últimas décadas (cit. en Veres 120). Si ese futuro del que Bloom hablaba es hoy, su pronóstico, a partir de la novela de Morales que aquí se aborda, es acertado.

Jorge Zúñiga, narrador tuxtleco nacido en 1988, publica en el año 2016 el libro titulado Un ballet violento, al que aquí atendemos por considerar que posee cualidades prodigiosas. Los relatos que conforman la obra de Zúñiga, leídos en conjunto, abordan el tema de la violencia en tres vertientes, desde mi perspectiva: la violencia del narcotráfico, el espectáculo de la violencia de la lucha libre mexicana y, por último, la concepción abstracta de la violencia. A partir de la investigación que un periodista está realizando acerca de la desaparición del famoso luchador Furia, conocemos la historia de este, sus inicios en la lucha libre y su pasado como integrante de una organización delictiva en Sinaloa; conocemos también a Torre, colega e íntimo amigo de Furia, quien ahora está cumpliendo una condena en la cárcel por haber defendido con exceso de violencia a Furia en una riña, de quien siempre estuvo enamorado; sabemos de Clara, el eterno amor de Furia, hija de un narcotraficante importante, así como de su bebé Romina, de La Cosa y de su hermano; en fin, conocemos el acontecer de diversos personajes con quienes se relaciona Furia entre la frontera con Estados Unidos, Sinaloa y la Ciudad de México, espacios en los que se desarrolla la obra, lo que nos va ayudando a los lectores a unir las piezas del rompecabezas. Además de distinguirse Un ballet violento por su prosa cuidada, por su minimalismo en el uso de descripciones y adjetivaciones, así como por su agilidad y dinamismo, señalo positivamente, por un lado, el juego de voces narrativas en su articulación y, por otro, el interesante abordaje de la violencia. Acerca del juego de voces narrativas presente en $U n$ ballet violento, puede decirse que Zúñiga utiliza distintos narradores en cada uno de los relatos que al sumarse edifican la obra, ${ }^{15}$ todos intradiegé-

${ }^{15}$ Hay una similitud en cuanto a esta obra y la de Mikel Ruiz, de la que se 
ticos. De esta manera se rechaza el narrador omnisciente característico de la literatura tradicional o clásica y se privilegia la narración versátil de la literatura contemporánea o moderna. En el primer relato, "La señal de la furia", por ejemplo, Torre dialoga con un interlocutor sin marca, en un principio desconocido, acerca de Furia, de su amor por él y del final de la época dorada de la lucha libre en México. Es a partir de su juicio que concebimos a Furia como un luchador de "cuerpo moreno y brillante" (Zúñiga 13) o que dudamos si es verdad que el hombre que encontraron muerto es Furia (Zúñiga 32). En el último relato, también desde una perspectiva particular, la de La Cosa, conocemos la versión de la historia en la que Furia se reencontró con Clara, la mujer a quien siempre amó, y ambos “Quisieron huir al otro lado, cruzar la frontera. Quisieron huir pero Clara nunca llegó a la cita, no quiso o no pudo" (58). Así, se presenta esta obra a modo de relatos individuales, con vivencias e hipótesis personales en referencia a sucesos de competencia colectiva y con registros y estilos distintos de lenguaje. Al mismo tiempo estamos ante una creación de corte literario que se va armando conforme avanzamos en su lectura, a partir de historias que se entrecruzan y nos invitan a sumar o rechazar teorías para llegar a conclusiones propias. El objetivo de Jorge Zúñiga al utilizar este formato puede ser precisamente liberar a los personajes del yugo del narrador y a su vez involucrar a los lectores en un proceso activo de lectura, concediéndonos así la posibilidad de convertirnos en una especie de coautores del libro.

En lo concerniente al abordaje de la violencia es interesante porque en la primera vertiente de las que mencioné párrafos atrás, es decir, la del narcotráfico, Zúñiga no hace copia de los éxitos editoriales de la llamada narcoliteratura, sino que teje con meticu-

habló con anterioridad. Un ballet violento también puede leerse como novela o puede leerse como relatos aislados. Sin embargo, no considero que la totalidad de los relatos, si optamos por esta configuración, sean autónomos, como sí ocurre con los apartados de Los hijos errantes (Ch'ayemal nich'nabiletik) de Mikel Ruiz, pues algunos de ellos requieren de un par de elementos para ser narraciones acabadas si se leen de forma independiente. 
losidad y astucia su propia propuesta. Conocido es un artículo de Rafael Lemus titulado "Balas de salva" en el que hace una crítica despiadada a la narconovela y a la narcoliteratura en general. En dicho artículo, Lemus manifiesta que este tipo de literatura utiliza la estrategia ordinaria del costumbrismo, del lenguaje coloquial y las tramas populistas; que hay demasiada picaresca y melodrama en ella; y que, en vez de apoyarse en la invención y el artificio, reproduce mecánicamente la realidad. Después, Eduardo Antonio Parra lo refuta y deja claro que generalizar es un error y que no todas las obras que se enmarcan en este subgénero son iguales ("Norte..."). Obviamente Parra es atinado en su respuesta, pero la observación de Lemus, sin tomar en cuenta lo categórico de sus afirmaciones, aplica para mucha de la literatura que aborda el tema del narco. No digo que $U n$ ballet violento se clasifique como narcoliteratura, sin embargo, es conveniente puntualizar que Zúñiga, al tratar este tema, se aleja por completo de estereotipos. Esto es visible, por ejemplo, cuando el jefe del Flaco (después Furia) le pone una trampa, porque cree que "le está jugando chueco", para que mate a Nosfe-Rata, luchador a quien el Flaco admira desmesuradamente, pero este no puede ejecutar la orden y comienza a llorar; después su compañero entiende de qué se trata todo y siente lástima por él. En Un ballet violento no hay narcotraficantes que visten Gucci o Versace, ni "trocas" o ríos de sangre; hay seres humanos, venganza y compasión. En la vertiente de la violencia en la lucha libre es peculiar cómo en $U n$ ballet violento, a propósito de su título, una de las propuestas es ver el deporte de la lucha libre, no tanto como una práctica violenta o que reproduce la violencia, sino como un espectáculo artístico bello y generador de goce estético como el ballet mismo. En la siguiente cita la evidencia:

Y nosotros repetimos su nombre a coro. A toda voz, sin temor alguno por desgarrarnos la garganta: ¡FU-RIA! ¡FU-RIA! ¡FU-RIA! Y yo sentí que el corazón se me iba a salir cuando lo vi lanzarse hacia el cuerpo inerte del Dr. Miedo, cuando lo vi extender los brazos y las piernas en el aire y descender como una maldición, como lo irreparable o el destino. Grité, grita- 
mos todavía con más fuerza, a punto de las lágrimas, mientras el réferi comenzaba la cuenta, ya por pura formalidad. (14)

Por último, acierta el autor al estimular reflexiones en la vertiente de la violencia abstracta, acerca de la muerte, de lo natural o lo antinatural que es para unos u otros la violencia, del uso de la violencia como antídoto contra sí misma, etcétera. Todo lo anterior a partir de que Torre defiende a Furia en un altercado y le da muerte a un hombre.

\section{Reflexiones finales}

Como fue posible confirmar, la existencia y abundancia de escritores jóvenes en el estado de Chiapas es un hecho. En estos hay sin duda un interés de manifestarse creativamente a través de la palabra y de perpetuar ideas, emociones, críticas, sentimientos. Sin embargo, es cierto que no todos poseen oficio y que solo algunos han logrado, con iniciativa, determinación y esmero, producir y publicar obras en las que la calidad, la novedad y la relevancia temática son evidentes, como las de Fernando Trejo, César Trujillo, René Morales, Mikeas Sánchez, Alexis de Ganges, Mikel Ruiz, Claudia Morales y Jorge Zúñiga. En el género poético pudimos comprobar la novedad, por ejemplo, en el caso de René Morales, quien escribe sobre muertes de migrantes a partir de un estilo único, que es el del texto híbrido; la calidad, en Trejo y Trujillo, uno presentando intertextualidad con obras pictóricas y otro relacionando estructuras lingüísticas y semánticas al hacer un buen uso de la metáfora; la relevancia, en Sánchez, quien reflexiona acerca de cuestiones íntimas del ser, como el alma y la relación con dios.

En el género narrativo, la novedad la vemos en Ruiz, pues este desarrolla personajes y temáticas indígenas, pero de una forma compleja, evitando caer en maniqueísmos; la calidad es comprobable en Ganges, quien relaciona estructuras de lenguaje y significación a partir del adecuado empleo de la ironía, así como en Claudia Morales, quien opta por contar una historia a través de la estructura fragmentada; y la relevancia temática es visible en Zúñiga a partir de las sugerentes reflexiones que nos ofrece concernientes a la 
violencia. Asimismo, reafirmamos la anotación de Jesús Morales Bermúdez de 1997 de que en Chiapas hay una evidente preferencia por parte de los escritores por el género poético. Pero también, de forma sorpresiva, encontramos que los narradores, paulatinamente, van en incremento. Y no solo esto, sino que muchos de ellos poseen una prosa soberbia y tienen propuestas más que interesantes, que sin duda están comenzando a refutar el mito de que Chiapas es tierra de poetas y no de narradores.

En general, este nuevo grupo de escritores jóvenes chiapanecos, como se observó ya, es un grupo que revela a través de sus textos un amplio bagaje de lecturas clásicas, nacionales, internacionales, experimentales; circunstancia posible en parte, al fácil acceso a la literatura que hoy en día se tiene. Pudimos darnos cuenta también que dialogan con la tradición, pero que hay siempre una intención de su parte de jugar con las formas, con las estructuras, con las temáticas, para crear obras con una identidad y estilo propios. Pese a que pudiera pensarse que al buscar novedad la calidad se sacrifica, los escritores jóvenes chiapanecos nos han demostrado que son capaces de ofrecer un producto original a la vez que bien realizado. También concluimos que las obras de dichos jóvenes no se quedan en el regionalismo. Su literatura es universal, trasciende límites. En ella se debaten temas como el arte, las relaciones humanas, los vicios y virtudes del hombre, la existencia de una divinidad, así como cuestiones que se vinculan más directamente con su geografía y época, como la migración, el mundo posmoderno y la violencia, pero que aun así abordan astutamente sin caer en localismos.

Por último, no resta sino subrayar que el Estado sigue estando en deuda con los escritores mexicanos. Requiere tomar medidas serias en apoyo de la literatura y el arte en general. Se reconocen también las acciones que instituciones como el CONECULTA hacen al ritmo y al modo en que le es posible. Pero sobre todo se aplaude a quienes no desisten en su empeño porque la literatura continúe siendo una pieza fundamental de la cultura y del pensamiento, como lo han hecho hasta ahora escritores jóvenes y no tan jóvenes del estado de Chiapas, tocando puertas, construyendo puentes, haciéndose camino, dejando de manifiesto la necesidad humana del arte. 


\section{Bibliografía}

Aguledo, Pedro Antonio. "Los ojos de la palabra. La construcción del concepto de ecfrasis ( $\mathrm{sic}$ ), de la retórica antigua a la crítica literaria". Lingüística y literatura, no. 60, 2011, pp. 75-92.

Bareras Gómez, Asunción. "El estudio de la ironía en el texto literario". Cuadernos de investigación filológica, no. 27-28, 2002, pp.243265.

Bourdieu, Pierre. Homo academicus. Siglo XXI, 2008.

Comte-Sponville, André. Sobre el cuerpo. Apuntes para una filosofía de la fragilidad. Editorial Paidós, 2010.

Culler, Jonathan. “¿Qué es la literatura, y qué importa lo que sea?”. Breve introducción a la teoría literaria. Oxford UP / Editorial Crítica S.L., 2000, pp. 29-55.

Ganges, Alexis de. Solo las cenizas. Universidad de Ciencias y Artes de Chiapas, 2009.

Gonzzalí Mayoral, Gustavo, compilador. Nueva literatura del Soconusco. Cuentos del taller coordinado por Marco Aurelio Carballo. CONECULTA, 2006.

Krauze, Enrique. "Rosario Castellanos, lúcida y escindida". Letras libres, 13 marzo 2017, www.letraslibres.com/espana-mexico/revista/rosario-castellanos-lucida-y-escindida

Lemus, Rafael. "Balas de salva". Letras Libres, 2005, www.letraslibres.com/mexico/balas-salva

Morales Bermúdez, Jesús. Aproximaciones a la poesía y a la narrativa de Chiapas. Universidad de Ciencias y Artes de Chiapas, 1997.

Morales, Claudia. No habrá retorno. CONECULTA, 2017.

Morales, Claudia y Fernando Trejo, coordinadores. "Trece Narradores de Chiapas (1978-1994)", número especial de Punto de Partida. La revista de los estudiantes universitarios, editado por la Universidad Nacional Autónoma de México, no. 196, marzo-abril, 2016.

Morales, René. Texas I love You. Anónima Editores, 2018.

Noguerol Jiménez, Francisca. "Híbridos genéricos: La desintegración del libro en la literatura hispanoamericana del siglo XX". Revista Rilce, 1999, pp. 239-250. 
Ocampo, Aurora. "El escribano de la vida". Revista de la Universidad de México, mayo 2016, pp. 47-49.

Ortega y Gasset, José. "Ensayo de estética a manera de prólogo". Obras completas. Tomo VI. Brindis y prólogos, 1964, pp. 247-264.

Parra, Eduardo Antonio. "Norte, narcotráfico y literatura". Letras Libres, 31 octubre 2005, www.letraslibres.com/mexico/norte-narcotrafico-y-literatura

Pulido, Luis Daniel y Fernando Trejo. Un manojo de lirios para el retorno. CONECULTA, 2015.

Rivera, Fabián y Fernando Trejo, compiladores. Porque algún día faltarán cuentos... Antología (otra) del cuento joven en Chiapas. CONECULTA / Ediciones del animal, 2007.

Ruiz, Mikel. Los hijos errantes (Ch'ayemal nich'nabiletik). CONECULTA / Centro Estatal de Lenguas, Arte y Literaturas Indígenas, 2014.

Sánchez, Mikeas. Y sabrás un día (Tumjama maka mujsi). CONECULTA / Centro Estatal de Lenguas, Arte y Literaturas Indígenas, 2006.

Singly, Francois de. "Las formas de terminar y de no terminar la juventud”. Revista de Estudios de Juventud, no. 71, 2005, pp. 111-121.

Trejo, Fernando. Ciervos. CONECULTA / Ediciones Atrasalante, 2015.

Trujillo, César. Evocación de la infancia. CONECULTA, 2018.

Veres Cortés, Luis. "Fragmentarismo y escritura: de la vanguardia a la metaliteratura". Sphera Pública, no. 10, 2010, pp. 103-122.

Von Ziegler, Jorge. "Nota introductoria". Eraclio Zepeda, 2009, pp. 3-5.

Zavala, Magda. "Globalización y literatura en América Central: escritores y editoriales". Intersecciones y transgresiones: propuestas para una historiografía literaria en Centroamérica, F \& G Editores, 2008, pp. 225-245.

Zúñiga, Jorge. Un ballet violento. CONECULTA, 2016. 